\title{
O FAZER NO TEATRO E O FAZER NA AULA DE TEATRO
}

Priscilla Amaral ${ }^{1}$

RESUMO: O presente artigo aborda questões sobre o Teatro na escola e as aulas de teatro, estabelecendo um vinculo entre elas. Assim, é papel da escola estabelecer os vínculos entre os conhecimentos escolares sobre a arte e os modos de produção e aplicação desses conhecimentos na sociedade. Trata-se de um ensino e aprendizagem de arte que poderá contribuir para que conhecer seja também divertirse, maravilhar-se, brincar com o desconhecido, arriscar hipóteses ousadas, trabalhar muito, esforçar-se e alegrar-se com descobertas.

PALAVRAS-CHAVE: Estudo; Teatro; Linguagem; Aprendizagem; Criação.

ABSTRACT: This article treats questions about the Theatre in school drama classes and establishing a bond between them. The school's role to establish the links between school knowledge about art and the modes of production and application of knowledge in society. A teaching and learning of art that can help you meet is also fun, wonder and play with the unknown, risking bold hypotheses, work hard, work hard and to rejoice in discovery.

KEYWORDS: Study; Drama; Language; Learning; Creating.
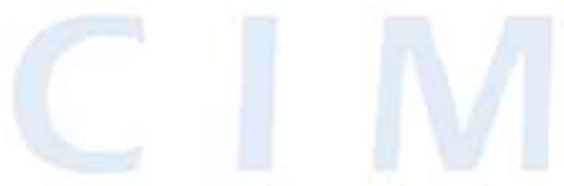

O ponto de partida em arte, pelo menos o meu ponto de partida, é que a obra de arte nunca morre.

Augusto Boal

\section{INTRODUÇÃO}

No presente momento ocorrem muitos debates e discussões no campo do ensino da Arte, que procuram pensar, analisar e refletir um pouco sobre o processo de ensino aprendizagem do fazer teatral, do fazer artístico. O que se pensa hoje é se a experiência teatral é ou não um fenômeno artístico. Mais especificamente, em uma aula de Teatro conduzida e feita em sala de aula, por professores não especialistas e os exercícios de improvisação aplicados pelos professores e feitos pelos alunos podem ser qualificados como ação teatral? E por quê?

\footnotetext{
${ }^{1}$ Mestranda em Artes, Educação e Historia da Cultura pela Universidade Presbiteriana Mackenzie (2010), possui Pós-Graduação em Linguagens da Arte pela Universidade de São Paulo - USP (2009), graduação em Artes Cênicas pela Universidade Anhembi Morumbi (2004), e em Pedagogia pela Universidade Presbiteriana Mackenzie (2008); participação em grupo de pesquisa da Universidade Presbiteriana Mackenzie (FOPEV). Atualmente é Organizadora Sócio Cultural, Arte-Educadora em Dança e Teatro e Pedagoga. Tem experiência na área de Educação, com ênfase nos Processos de Aprendizagem das Artes, na Educação Infantil e nas séries iniciais, atuando principalmente nos seguintes temas: Artes no ensino fundamental e Organização Sócio Cultural. Contato: prittybombom@hotmail.com
} 
Nos últimos anos tem se colocado em voga uma nova perspectiva para o ensino artístico, onde se procura apresentar um conteúdo legitimado a fim de constituir uma disciplina. O propósito disto é que seja formalizada dentro da "grade" curricular como matéria própria, como área de conhecimento que traz um arcabouço único para a formação do individuo, e, portanto precisa de uma prática pedagógica muito expressiva e especifica. Por esse ponto de vista a Arte se mostra como uma disciplina única independente e com fim em sim mesma, e não como instrumento e ou ferramenta para outras. Se faz necessária como personagem principal no ensino e no processo de aprendizagem do fazer artístico para desenvolver por sim só vários elementos necessários a formação do ser como a sociabilidade, a própria alfabetização, a coordenação motora fina e grossa e quaisquer disciplinas que sejam utilizadas dentro de sala de aula.

Este processo é bem visível nas diferentes propostas de Arte e de Educação, que estão acontecendo em muitas partes do mundo. No Brasil, por exemplo, os PCNs relativos ao Ensino das Artes na Educação Básica, estabelecem três conjuntos de competências e habilidades a serem desenvolvidas no ensino de Arte: a representação e comunicação, que correspondem ao fazer artístico; a investigação e compreensão, referentes à apreciação de Arte, que por sua vez, estão ligadas à análise estética e crítica de Arte e, ainda, a contextualização sociocultural, equivalente à compreensão da história da Arte.

O que podemos ver é que o ensino da Arte quer unificar a função formativa do ensino artístico um caráter epistemológico. Fora o objetivo de criar uma experiência expressiva e proporcionar noções básicas da linguagem a que se refere e vem reivindicando para si a competência de investigar o fenômeno artístico, como ele se caracteriza e se produz, sistematizando suas relações.

Assim, incluídas neste debate, encontrasse uma problematização sobre o ato artístico, e ainda sobre uma questão sobre o que transforma um evento qualquer, seja ele som, movimento, palavra, ação, gesto, em um evento de cunho artístico.

Não se trata aqui de estabelecer questionamentos sobre se o aluno é ou não um artista ou fazer algum juízo de valor sobre a criação na sala de aula. 
Não se pretende discutir sobre se há presença de um fazer artístico do artista e um fazer artístico do aluno e ou pedagógico ou quiçá elementos que os diferenciem ou os igualem.

Este Artigo procura refletir sobre o acontecimento do ato teatral na sala de aula. Procura levantar as condições básicas da teatralidade, e procura-las nas dinâmicas dos alunos para assinalar que "potencialmente" a aula de teatro é sim Teatro.

Esta possível reflexão será conduzida pautada em autores que desenvolvem uma pesquisa qualitativa a área, por exemplo, J. Guinsburg, Ana Mae Barbosa, Ricardo Japiassu.

\section{A ARTE COMO CONHECIMENTO}

A Arte tem em comum com outras áreas de conhecimento o caráter de busca de sentido, de criação, de inovação. Principalmente por seu "ato criador" em qualquer forma de criação e conhecimento humano, ou nas ligações que o homem faz para criar e dar sentido a algo em potencial, o homem estrutura e organiza o mundo, dialogando com os desafios que se apresentam, em constante processo de transformação pelo qual o mesmo passa e também pelo que passa o mundo ao seu redor .

Há uma necessidade entre os seres humanos em procurar diferenciar e analisar os fenômenos da natureza, o ciclo da água, das estações, os astros no céu, e as diferenças entre plantas e animais, as relações interpessoais, sociais e políticas, claro não podemos esquecer as econômicas, para entender seu lugar no mundo, buscando as significação da vida tanto a artes quanto as ciências conseguem responder a essa urgência em buscar significações na construção de objetos de conhecimento que juntamente com as relações acima citadas, formam um grande conjunto de manifestações simbólicas das culturas.

Arte e Ciência são produtos que exprimem as experiências e representações das distintas culturas, que se modificam e transmutam através dos tempos, criando um caminho para a historia humana. A ideia da ciência e das Artes como disciplinas independentes é produto recente da cultura ocidental. 
Por meio da Arte é possível desenvolver a percepção e a imaginação, apreender a realidade do meio ambiente, desenvolver a capacidade crítica, permitindo ao indivíduo analisar a realidade percebida e desenvolver a criatividade de maneira a mudar a realidade que foi analisada. (BARBOSA, 2003, p.18)

Nas sociedades antigas (primitivas) as formas artísticas não existem desconectadas da vida social e atuam como atividades da própria comunidade. Da mesma forma em que alguns rituais primitivos são organizados e celebrados pelo coletivo - cantos de trabalho (negras escravas), oferendas aos deuses pelas boas colheitas (nações indígenas), ou um ano sem problemas de ordem ambiental (gregos), outros são associados exclusivamente aos curandeiros, sacerdotes e ou chefes das nações indígenas.

No entanto, os conhecimentos do curandeiro não estão dissonantes dos rituais que se apresentam no canto e ou na dança, ou até nas invocações (orações/preces), que são considerados ancestrais das nossas formas artísticas. Não existe separação entre a Arte, a Ciência e a Vida.

Após o Renascimento, Arte e Ciência foram consideradas no Ocidente como áreas de conhecimento distintas, ocasionando concepções que diziam que a ciência era resultado do pensamento totalmente racional e as Artes parte de um pensamento que se associava a sensibilidade. Essa visão dicotômica se contradiz no pensamento dos dias atuais, quando se entende que a razão e o sentimento são áreas do conhecimento humano, e que não podem ser desassociadas.

A verdade cientifica mobiliza-se e, torna-se uma verdade "provisória" e que se aproxima muito estruturalmente os produtos da ciência e da Arte em si.

Esse dinamismo entre o e homem que apreende a realidade de forma mais poética e o outro que a compreende de forma mais cientifica são vias peculiares de aceso ao conhecimento que devem andar em paralelo. Há uma tendência cada vez mais acentuada, nas investigações recentes para dimensionar o complemento entre arte e ciência, conseguindo assim precisar a diferença entre eles, e paralelamente integrando-as em um novo conceito de ser humano.

O processo criador e a própria criatividade são os objetos de estudo dos psicólogos, dos educadores, dos sociólogos, dos antropólogos, e enfim da maioria dos estudiosos da área de humanas. Esse processo criador pode 
acontecer tanto na Ciência quanto na Arte, que se mostra à consciência do ser criador, vindo à tona, sem previsão, mas sendo sempre posterior a um período de trabalho e reflexão sobre o assunto.

Ajudar aos professores a compreenderem como as crianças
inventam veículos autônomos de liberdade expressiva, de
liberdade cognitiva, de liberdade simbólica e vias de
comunicação apresentam objetivos educacionais gerais, mas
não formulam objetivos específicos para cada projeto ou
atividade de antemão. Em vez disso, formulam hipóteses sobre
o que poderia ocorrer com base em seu conhecimento das
crianças e das experiências anteriores feitas dentro de sala de
aula. (BRANDÃO, 2005 p. 158)

Então se pressupõe que seja de fundamental importância que a escola estabeleça vínculos entre esses conhecimentos dentro da sociedade. Por isso um ensino e uma aprendizagem em arte e em ciência têm que se processar criadoramente par que o conhecer seja também interessante e instigante ao mesmo tempo.

Para que o aluno desfrute de seu próprio conhecimento, e este esteja relacionado com a formação do aluno do ensino básico.

\section{O FAZER TEATRAL}

Para que o gesto ou uma situação seja assinalada pela substantividade teatral é a intenção e ser Teatro. O autor J. Guinsburg (2001) estabelece que a marca fundamental do teatro é sua intencionalidade. O "ato" teatral não é aleatório, nem um mero acaso o seu fazer, esclarece que apesar de muitas circunstancias na vida terem características teatrais, como uma gafe, um tropeço, uma discussão, isso não se caracteriza como Teatro, pois estão desprovidas de uma intencionalidade e de um projeto de suspender o "fluxo da vida" e de produzir um parecer ser. Neste caso o termo teatral atribuído ao gesto e ou a ação caracteriza-se por uma natureza adjetiva e não substantiva.

Em uma aula "normal" de teatro acontecem exercícios de improvisação, acontecem jogos dramáticos, jogos teatrais, trabalhos corporais, trabalhos vocais, neste momento está claro a intenção de não estabelecer nenhum vinculo com a vida real, há sim uma necessidade estabelecer outra realidade outra possibilidade de "eus". 
Por exemplo, utilizando jogos teatrais, uma atividade conceituada por Viola Spolin, que é uma pesquisadora americana que sistematizou o método de criação teatral, utilizando-se de exercícios cênicos, em que um grupo de alunos recebem o nome de uma jogo (basquete) e terão que faze-lo com uma bola imaginaria, como se estivessem verdadeiramente jogando.

Embora todos os alunos estejam dentro da sala de aula o jogo deve acontecer verdadeiramente como se estivessem em uma quadra de basquete, com uma bola real, neste momento os alunos assumem que a sala de aula possa ser uma quadra de basquete, enfim ou o jogo que seja.

Nas atividades corporais, os alunos assumem gestos e movimentos que não são do seu próprio repertorio, e criam outro espaço e uma forma de estar no mundo.

Isto pode acontecer em uma dinâmica muito simples como "andar pela sala" utilizando os níveis, trabalhando torções, testando bases de apoio e começando a fazer exercícios mais complexos com separados em duplas um tenta tocar o dedo indicador do outro com os olhos vendados.

Contudo, Guinsburg (2001) diz que não basta a intencionalidade, o "evento Teatral" é o cruzamento entre quem comunica e quem assiste a comunicação dada. Aponta a existência do Texto, do ator, e do publico para que esse cruzamento seja estabelecido, essas peças são fundamentais para constituir o ato teatral.

De acordo com o autor esses elementos constituem um sistema aberto sujeito a diversos enfoques e combinações. O que concerne ao texto reconhece como "material textual" todo o conjunto de elementos, que é atribuído um significado, e passível de leitura de acordo com a linguagem vigente, e não só os textos dramáticos. Quanto ao ator, é uma figura preestabelecida no sentido em que estabelece uma relação consentida entre um que assume um papel e outro que o acolhe, o espectador. Sobre o terceiro elemento, que liga estes dois outros o público, pois o é somente quando assiste a ação teatral que se completa e se instaura como tal.

Observadas aqui os três elementos para se estabelecer um evento teatral é preciso encontra-las no processo de ensino de Teatro. 


\section{O ATOR}

Esse elemento passa a figurar na cena teatral juntamente com o teatro, pois o ato estético com formação inicial na Grécia. Tem seu alicerce no binômio Ator-Espectador. Sem esse elemento não há teatro. O aparecimento do primeiro ator na historia é do poeta Téspis, que representava vários papeis, simultaneamente em suas peças. Era muito comum não reconhecerem os atores nas cenas gregas, pois os mesmos utilizavam-se de vários acessórios e mascaras e figurinos muito alongados, também tamancos de madeira.

Os tragediógrafos gregos representavam o papeis que escreviam muito tempo depois Sófocles desvinculou o Ator do Autor. Desde o surgimento do teatro as mulheres não poderiam representar todos os papeis inclusive os femininos eram representados por homens.

Só na commedia dell'arte que as mulheres começam a atuar com teatro de rua. Quando o império Romano toma conta da cultura grega, assimila um teatro já decadente, então o público romano opta por ver espetáculos circenses, jogos de luta e competitivos e diferentes formas de corrida. Não valorizando mais a Arte Dramática, sendo assim o ator começa a migrar e especializar-se em mimica, dança e acrobacia, nesta ordem. Os mais interessados na Arte Dramática migram para o campo compondo assim grupos mambembes que caiam no gosto popular.

No Brasil as ideias sobre o conceito de ator foram trazidas por Bertolt Brecht, através de Augusto Boal, permitindo que o ator trabalhe com 0 distanciamento, e com diferentes papeis. Todos podem ser atores é o que propõem Brecht e Boal, o teatro é um ato estético efetuado de maneira coletiva.

\section{O TEXTO}

Nesse sentido do texto aqui empregado é amplamente discutido como sendo, o que é passível de leitura, com desígnios de uma ordem referida, então pode-se considerar texto materiais textuais como a palavra, o gesto, a musica, o códigos e etc. 
Em todas as aulas de teatro há inúmeros códigos que são mostrados e que podem ser considerados textos. Os diferentes modos de andar, se movimentar, de falar, de se expressar são elementos que compõem formas de textualização, que muitas vezes refletem a historia pessoas do aluno, seu contexto histórico e seus valores.

O texto está evidenciado no trabalho de composição do personagem pois é ele que mostra as características físicas, emocionais e ou psicológicas do personagem para sua composição pelo ator .

Mesmo que esteja implícito na atividade do fazer teatral quem é esse personagem, com jogos de improvisação corporal há uma procura de representar aquilo que está escrito no texto, tornando-o fator indispensável para essa pratica.

\section{O ESPECTADOR}

O espectador assume o papel e aceita compartilha com o ator esse mundo em criado através de uma linha imaginaria entre os atuantes e os observadores. Neste momento está dado o relacionamento, a rede de reações que se estabelece neste momento é o que atribui caráter único para cada apresentação, que jamais será igual a outra pois os comprometimentos preestabelecidos se renovam a cada encenação e ou atuação.

Na sala de aula o público será o próprio aluno ou os próprios alunos que se revezaram entre a atuação e a observação. Ambas trafegam pelas mesmas relações que percorrem o ator e seu público.

Além disso, na sala de aula há um momento de contribuições e de falas para acrescentar a criação de cada cena, na forma de critica e ou de sugestão, ou nas discussões sobre o que foi encenado e o que foi compreendido pelo público, isto é de vital importância para a concepção do que se tem por teatro essa tríade tem que existir para o ato teatral se completar.

\section{CONCLUSÃO}

Desta forma se faz necessário que o professor de Teatro especialista ou não, ofereça uma prática da linguagem, que faça com que essa pratica seja 
efetiva e singular para oferecer aos seus alunos uma vivencia significativa no fazer teatral.

Que esse professor articule outra linguagem, paralelize conceitos e as inter-relações entre eles; que ele discuta com seus alunos a prática exercida, e os porquês desta pratica ser assim e não de outra maneira. E sobretudo que esse professor permita que seu aluno descubra estes princípios imanentes da própria natureza teatral no próprio exercício da criação, da ação no fazer artístico, pois um dos pressupostos do ensino de Arte é que embora nem todos necessariamente se constituam artistas, qualquer individuo pode produzir arte, individual e ou coletivamente, desde que tenha disponível a linguagem e a execute de maneira integral.

\section{REFERÊNCIAS BIBLIOGRÁFICAS}

BARBOSA, Ana Mae. A imagem no Ensino da Arte. Porto Alegre: lochpe, 1997.

Arte educação: conflitos/acertos. São Paulo: Max Limonard, 1984.

Arte-educação no Brasil. São Paulo: Perspectiva, 2003.

BIASOLI, Carmen. A formação do professor de Arte: do ensaio à encenação. Campinas: Papirus, 1999.

BRANDÃO, Carlos Rodrigues. O que é Educação. $33^{a}$ ed. São Paulo: Brasiliense, 2005.

GUINSBURG, Jacob. Da Cena em Cena. São Paulo: Perspectiva, 2001.

SANTOS, Vera Lúcia B. dos. Brincadeira e Conhecimento: do Faz-de-conta à Representação Teatral. Porto Alegre: Mediação, 2002.

SPOLIN, Viola. Improvisação para o Teatro. São Paulo: Perspectiva, 1982. 